OPEN ACCESS

Check for updates

\title{
Effectiveness of management strategies for uninvestigated dyspepsia: systematic review and network meta-analysis
}

\author{
Leonardo H Eusebi, ${ }^{1}$ Christopher J Black, ${ }^{2,3}$ Colin W Howden, ${ }^{4}$ Alexander C Ford ${ }^{2,3}$
}

${ }^{1}$ Department of Medical and

Surgical Sciences, University of

Bologna, Bologna, Italy

${ }^{2}$ Leeds Gastroenterology

Institute, St James's University

Hospital, Leeds, UK

${ }^{3}$ Leeds Institute of Medical

Research at St James's,

University of Leeds, Leeds, UK

${ }^{4}$ Division of Gastroenterology

and Hepatology, Department

of Medicine, University of

Tennessee College of Medicine,

Memphis, TN, USA

Correspondence to: A C Ford

Leeds Gastroenterology Institute,

St James's University Hospital,

Leeds LS9 7TF, UK

alexf12399@yahoo.com

(or @alex_ford12399 on Twitter;

ORCID 0000-0001-6371-4359)

Additional material is published online only. To view please visit the journal online.

Cite this as: BMJ 2019;367:16483 http://dx.doi.org/10.1136/bmj.l6483

Accepted: 7 November 2019

\section{ABSTRACT}

OBJECTIVE

To determine the effectiveness of management strategies for uninvestigated dyspepsia.

DESIGN

Systematic review and network meta-analysis.

DATA SOURCES

Medline, Embase, Embase Classic, the Cochrane Central Register of Controlled Trials, and clinicaltrials. gov from inception to September 2019, with no language restrictions. Conference proceedings between 2001 and 2019.

\section{ELIGIBILITY CRITERIA FOR SELECTING STUDIES}

Randomised controlled trials that assessed the effectiveness of management strategies for uninvestigated dyspepsia in adult participants (age $\geq 18$ years). Strategies of interest were prompt endoscopy; test for Helicobacter pylori and perform endoscopy in participants who test positive; test for $H$ pylori and eradication treatment in those who test positive ("test and treat"); empirical acid suppression; or symptom based management. Trials reported dichotomous assessment of symptom status at final follow-up ( $\geq 12$ months).

RESULTS

The review identified 15 eligible randomised controlled trials that comprised 6162 adult participants. Data were pooled using a random effects model. Strategies were ranked according to $P$ score, which is the mean extent of certainty that one management strategy is better than another, averaged over all competing strategies. "Test and treat" ranked first (relative risk of remaining symptomatic 0.89 , $95 \%$ confidence interval 0.78 to 1.02 , P score 0.79 ) and prompt endoscopy ranked second, but performed similarly $(0.90,0.80$ to 1.02 , P score 0.71$)$. However, no strategy was significantly less effective than "test and treat." Participants assigned to "test and treat" were significantly less likely to receive endoscopy (relative risk $v$ prompt endoscopy $0.23,95 \%$ confidence interval 0.17 to 0.31 , P score 0.98 ) than all other strategies, except symptom based management (relative risk $v$ symptom based management 0.60 , 0.30 to 1.18). Dissatisfaction with management was significantly lower with prompt endoscopy (P score $0.95)$ than with "test and treat" (relative risk $v$ "test and treat" $0.67,0.46$ to 0.98 ), and empirical acid suppression (relative risk $v$ empirical acid suppression $0.58,0.37$ to 0.91 ). Upper gastrointestinal cancer rates were low in all trials. Results remained stable in sensitivity analyses, with minimal inconsistencies between direct and indirect results. Risk of bias of individual trials was high; blinding was not possible because of the pragmatic trial design.

\section{CONCLUSIONS}

"Test and treat" was ranked first, although it performed similarly to prompt endoscopy and was not superior to any of the other strategies. "Test and treat" led to fewer endoscopies than all other approaches, except symptom based management. However, participants showed a preference for prompt endoscopy as a management strategy for their symptoms.

SYSTEMATIC REVIEW REGISTRATION

PROSPERO registration number CRD42019132528.

\section{Introduction}

Dyspepsia is a common condition that could involve a variety of upper gastrointestinal symptoms, but the main symptom is upper abdominal pain or discomfort. ${ }^{1}$ At some point in their lives, one in five adults report epigastric pain, early satiety, postprandial distress, and other associated upper gastrointestinal symptoms, such as heartburn, regurgitation, or nausea. Although dyspepsia is not associated with higher mortality risk, ${ }^{23}$ the condition is chronic in many people ${ }^{4}$ and follows a fluctuating course. ${ }^{5-7}$ Dyspepsia has a substantial impact on patients' quality of life, ${ }^{8}$ and is associated with more time off work and lower productivity at work, and greater medical and prescription drug costs each year. ${ }^{910}$ The financial implications for society as a whole are huge. ${ }^{11}$

Approximately $40 \%$ of people with dyspepsia symptoms will consult a primary care physician. ${ }^{12}$ The physician has to make a decision about how best to manage the individual patient. Patients with 
uninvestigated dyspepsia and alarm features, such as dysphagia, weight loss, or anaemia, or those older than a certain age threshold, require urgent endoscopy. However, the management of uninvestigated dyspepsia in the absence of alarm features represents a classic medical decision making problem because several strategies exist. These strategies include prompt endoscopy for all patients; test for Helicobacter pylori and perform endoscopy in those who test positive ("test and scope"); test for $H$ pylori and eradication treatment in those who test positive ("test and treat"); empirical acid suppression for all patients; or symptom based management according to guideline recommendations or the physician's usual practice.

The effectiveness of these different strategies has been studied in numerous pragmatic randomised controlled trials. ${ }^{13-17}$ However, there is equipoise among various strategies and uncertainty as to which strategy is best to use first line. Trial based metaanalyses, and even individual patient data metaanalyses, have been unable to resolve this uncertainty completely. Although prompt endoscopy is expensive, it appears to be superior to empirical acid suppression or symptom based management when comparing the effect on symptoms in some patients, ${ }^{15} 18$ and was superior to "test and treat" in an individual patient data meta-analysis. ${ }^{19}$ However, it is unlikely to be cost effective, ${ }^{19}$ and therefore is not recommended as first line treatment in management guidelines for uninvestigated dyspepsia. ${ }^{20} 21$ Another individual patient data meta-analysis of "test and treat" versus empirical acid suppression showed no difference in either costs or effects between the two strategies. ${ }^{22}$ As a result, guidelines disagree about which approach should be used for the initial management of uninvestigated dyspepsia (table 1). ${ }^{20-23}$

Network meta-analysis might be able to resolve some of this uncertainty because the methods used allow indirect and direct comparisons across different randomised controlled trials, which increases the number of participants' data available for analysis. Additionally, network meta-analysis allows a credible ranking system to be developed that shows the effectiveness of different management strategies, even in the absence of trials making direct comparisons, which can help to inform clinical decision making. Therefore, we conducted a network meta-analysis of all available randomised controlled trials that have compared five management strategies for uninvestigated dyspepsia.

\section{Methods}

\section{Search strategy and study selection}

We searched Medline (from 1947 to September 2019), Embase, Embase Classic (from 1947 to September 2019), and the Cochrane Central Register of Controlled Trials to identify potential studies. In addition, we searched national guidelines for the management of dyspepsia, clinicaltrials.gov for unpublished trials, and supplementary data for potentially eligible studies (all up to September 2019). Conference proceedings
(Digestive Disease Week, American College of Gastroenterology, United European Gastroenterology Week, and the Asian Pacific Digestive Week) between 2001 and 2019 were hand searched to identify studies published only in abstract form. Finally, we performed a recursive search by using the bibliographies of all obtained articles.

Eligible randomised controlled trials examined the effect of various management strategies for uninvestigated dyspepsia (prompt endoscopy, "test and treat," "test and scope," empirical acid suppression, or symptom based management) in adult participants (age $\geq 18$ years). The definition of dyspepsia was broad and included any upper gastrointestinal symptoms referable to the gastroduodenum. We only considered randomised controlled trials to be eligible when they examined the effectiveness of one of the strategies of interest and compared it with at least one of the other strategies. Because dyspepsia is a chronic fluctuating condition, ${ }^{4}$ a minimum follow-up of 12 months was required. We extracted all endpoints at the final point of follow-up to ensure as much homogeneity as possible among individual trial results, and to avoid overestimating the effectiveness of one management strategy relative to another. Studies had to report a dichotomous assessment of symptom status at the final point of follow-up (box 1). The study protocol was published on the PROSPERO international prospective register of systematic reviews (registration number CRD42019132528).

Two investigators (LHE and ACF) conducted the literature search independently from each other. We report the search strategy in the supplementary materials. There were no language restrictions. Two investigators (LHE and ACF) evaluated all abstracts identified by the search for eligibility, again independently from each other. We obtained all potentially relevant papers and evaluated them in more detail by using predesigned forms to assess eligibility independently, according to the predefined criteria. We translated foreign language papers if required. Disagreements between investigators were resolved by discussion.

\section{Outcome assessment}

We assessed the effectiveness of all five management strategies of uninvestigated dyspepsia by comparing the probability of being symptomatic at the final point of follow-up. Additionally, because individual trials reported several other secondary endpoints, we were able to assess the likelihood of participants receiving endoscopy in each treatment arm, and dissatisfaction with management. Finally, we recorded rates of upper gastrointestinal cancer detection.

\section{Data extraction}

Two investigators (LHE and ACF) extracted all data independently onto a Microsoft Excel spreadsheet (XP professional edition) as dichotomous outcomes (symptomatic or asymptomatic at final point of follow-up). For all included studies, we also extracted 
the following data for each trial, when available: country of origin, setting, duration of follow-up, age range of included participants, proportion of female participants, proportion of participants with $H$ pylori infection, and exact management strategy used. Data were extracted as intention to treat analyses, with dropouts assumed to be treatment failures (that is, symptomatic at final point of follow-up), by using the total number of participants randomised to each treatment arm as the denominator, wherever trial reporting allowed. Given the duration of follow-up in individual trials, we also performed a sensitivity analysis by using a per protocol analysis and including all participants with reported evaluable data at the final point of follow-up.

\section{Quality assessment and risk of bias}

This assessment was performed at the study level by two investigators (LHE and ACF) independently by using the Cochrane risk of bias tool. ${ }^{24}$ Disagreements were resolved by discussion. We recorded the methods used to generate the randomisation schedule and conceal treatment allocation. We also noted whether blinding was implemented for participants, personnel, and outcomes assessment, whether there was evidence of incomplete outcomes data, and whether there was evidence of selective reporting of outcomes.

\section{Data synthesis and statistical analysis}

We performed a network meta-analysis by using the frequentist model with the statistical package "netmeta" (version 0.9-0, https://cran.r-project.org/web/packages/ netmeta/index.html) in $\mathrm{R}$ (version 3.4.2). Firstly, we performed a pairwise meta-analysis of the raw data (supplementary figs 1-3) to convert them from contrast based format to long format, and to generate the treatment effect and standard error of the treatment effect for each pairwise treatment comparison. Subsequently, we used these data to conduct a network meta-analysis by using netmeta, which assumes a common $\tau^{2}$ for all pairwise comparisons. The estimate of $\tau^{2}$ is based on the generalised DerSimonian-Laird method. ${ }^{25}$ Uncertainty is not accounted for fully in this model because the distribution of parameters such as the between study variance is not assumed. In multiarm studies, all pairwise comparisons are considered, not only those with a common comparator, but are downweighted. ${ }^{25}$ We reported the network meta-analysis according to the PRISMA (preferred reporting items for systematic reviews and meta-analyses) extension statement for network meta-analyses. ${ }^{26}$ Network meta-analysis results usually give a more precise estimate compared with results from standard, pairwise analyses, ${ }^{27} 28$ and can rank management strategies to inform clinical decisions. $^{29}$

We examined the symmetry and geometry of the evidence by producing a network plot with node and connection size corresponding to the number of study participants and number of studies, respectively. We produced comparison adjusted funnel plots to explore publication bias or other small study effects for all available comparisons by using Stata (version 14, Stata, College Station, TX). This is a scatterplot of effect size versus precision, measured through the inverse of the standard error. Symmetry around the effect estimate line indicates the absence of publication bias, or small study effects. ${ }^{30}$ We produced a pooled relative risk with 95\% confidence interval to summarise the effectiveness of each management strategy tested by using a random effects model as a conservative estimate. We used the relative risk of remaining symptomatic at the final point of follow-up; when the relative risk is less than one and the $95 \%$ confidence interval does not cross one, there is a substantial benefit of one management strategy over another. Because there were direct comparisons between all of the management strategies, we were able to perform consistency modelling to check the agreement between direct and indirect evidence. ${ }^{31}$

Many meta-analyses use the $\mathrm{I}^{2}$ statistic to measure heterogeneity, which ranges between $0 \%$ and $100 \%{ }^{32}$ This statistic is easy to interpret and does not vary with the number of studies. However, the $\mathrm{I}^{2}$ value can increase with the number of patients included in the meta-analysis. ${ }^{33}$ Therefore, we assessed global statistical heterogeneity across all comparisons using the $\tau^{2}$ measure from the netmeta statistical package.

\begin{tabular}{|c|c|c|c|}
\hline Guideline & When to endoscope & When to use "test and treat" & When to use empirical acid suppression therapy \\
\hline $\begin{array}{l}\text { ACG and CAG } 2017 \\
\text { (North America) }^{20}\end{array}$ & $\begin{array}{l}\text { First line in people aged } \geq 60 \text { years; strength of } \\
\text { recommendation: conditional; level of evidence: } \\
\text { very low. First line in those aged } \geq 60 \text { years with } \\
\text { alarm features; strength of recommendation: } \\
\text { conditional; level of evidence: moderate }\end{array}$ & $\begin{array}{l}\text { First line in those aged < } 60 \text { years; likely to be } \\
\text { cost effective even with low rates of infection } \\
\text { because of reduction in gastric cancer rates in } \\
\text { infected individuals; strength of recommenda- } \\
\text { tion: strong; level of evidence: high }\end{array}$ & $\begin{array}{l}\text { First line in those aged }<60 \text { years if } H \text { pylori neg- } \\
\text { ative, or in those who remain symptomatic after } \\
\text { eradication therapy; use empirical proton pump } \\
\text { inhibitor treatment at standard dose; strength of } \\
\text { recommendation: strong; level of evidence: high }\end{array}$ \\
\hline $\begin{array}{l}\text { NICE } 2014 \text { (England } \\
\text { and Wales) }\end{array}$ & $\begin{array}{l}\text { First line in people aged } \geq 55 \text { years with weight } \\
\text { loss and dyspepsia; consider when Helicobacter } \\
\text { pylori eradication or empirical acid suppression } \\
\text { fails; strength of recommendation: "offer"*; level } \\
\text { of evidence: high }\end{array}$ & $\begin{array}{l}\text { First line in people with dyspepsia; if this fails } \\
\text { use empirical acid suppression with full dose } \\
\text { proton pump inhibitor; strength of recommenda- } \\
\text { tion: "offer"*; level of evidence: high }\end{array}$ & $\begin{array}{l}\text { First line in people with dyspepsia; use empirical } \\
\text { full dose proton pump inhibitor treatment for four } \\
\text { weeks; if this fails use "test and treat"; strength } \\
\text { of recommendation: "offer"*; level of evidence: high }\end{array}$ \\
\hline $\begin{array}{l}\text { Asia-Pacific Working } \\
\text { Party } 1998^{23}\end{array}$ & $\begin{array}{l}\text { First line in people aged 35-55 years (depend- } \\
\text { ing on risk of gastric cancer in region) or alarm } \\
\text { features (any age); if } \mathrm{H} \text { pylori eradication or em- } \\
\text { pirical acid suppression fails consider in younger } \\
\text { patients; strength of recommendation: not stated; } \\
\text { level of evidence: not reported }\end{array}$ & $\begin{array}{l}\text { Consider if empirical acid suppression fails; } \\
\text { in areas with high prevalence of } H \text { pylori this } \\
\text { strategy is unlikely to be beneficial; strength of } \\
\text { recommendation: not stated; level of evidence: } \\
\text { not reported }\end{array}$ & $\begin{array}{l}\text { First line for young patients with no alarm features; } \\
\text { either proton pump inhibitor or histamine } 2 \text { recep- } \\
\text { tor antagonists at standard dose for two to four } \\
\text { weeks; strength of recommendation: not stated; } \\
\text { level of evidence: not reported }\end{array}$ \\
\hline
\end{tabular}


Box 1: Eligibility criteria

- Randomised controlled trials

- Adults (aged $\geq 18$ years)

- Uninvestigated dyspepsia, before first investigation

- Compared strategy of interest with at least one other strategy: prompt endoscopy, "test and scope," "test and treat," empirical acid suppression, or symptom based management

- Minimum follow-up duration of 12 months

- Dichotomous assessment of dyspeptic symptoms at minimum of 12 months

Estimates of $\tau^{2}$ of approximately 0.04, 0.16, and 0.36 are considered to represent a low, moderate, and high degree of heterogeneity, respectively. ${ }^{34}$ We assessed inconsistency in the network analysis by comparing direct and indirect evidence, when available, by producing a network heat plot. ${ }^{3135}$ These plots have grey squares, which represent the size of the contribution of the direct estimate in columns, compared with the network estimate in rows. ${ }^{35}$ The coloured squares around these represent the degree of inconsistency, with red squares indicating "hotspots" of inconsistency. We planned to remove studies that introduced any red "hotspots" and to repeat the analyses to investigate sources of potential inconsistency. We also applied the $\chi^{2}$ test of the $\mathrm{Q}$ statistic to test for inconsistency, under the assumption of a full design by treatment interaction random effects model. ${ }^{3536}$ Finally, we tested for local inconsistency by splitting the network estimates into the contribution of direct and indirect evidence, and looking for any statistically significant differences.

We ranked management strategies according to their P score, which is between 0 and 1 . P scores are based solely on the point estimates and standard errors of the network estimates, and measure the mean extent of certainty that one management strategy is better than another, averaged over all competing strategies. ${ }^{37}$ Higher scores indicate a greater probability of the strategy being ranked as best, ${ }^{37}$ but the magnitude of the $\mathrm{P}$ score should be considered in addition to the rank. Because the mean $\mathrm{P}$ score is always 0.5, individual strategies that cluster around this score are likely to be of similar effectiveness. However, when interpreting the results, it is also important to take into account the relative risk and corresponding 95\% confidence interval for each comparison, rather than relying on rankings alone. ${ }^{38}$ In our primary analysis, we pooled data for the risk of being symptomatic at the final point of follow-up in each study for all included randomised controlled trials by using an intention to treat analysis. We also performed a per protocol analysis, and conducted analyses of the likelihood of receiving endoscopy, dissatisfaction with management among participants, and rates of upper gastrointestinal cancer.

We compared the relative effectiveness of all five management strategies using the "NetMetaXL" tool running in WinBUGS (version 1.4, Imperial College and MRC, London), ${ }^{39}$ which uses Bayesian methods. We used a random effects model with vague (uninformative) priors to achieve a conservative estimate of relative efficacy. Strategies were ranked according to their surface under the cumulative ranking curve value, which is comparable to the P score used in the frequentist model of our primary analyses. ${ }^{37}$ There were no differences in rankings among approaches, and therefore, for clarity, we only report the frequentist model in this paper, which is consistent with our approach for reporting previously published network meta-analyses. ${ }^{40-44}$

Because one of the studies was a cluster randomised trial, ${ }^{45}$ with patients assigned to treatment strategy by primary care practice, rather than randomised individually, we used the cluster size and the intra cluster correlation coefficient to reduce the size of the trial to its "effective sample size," which was 440 participants (233 "test and treat" and 207 empirical acid suppression), before any data pooling was carried out. ${ }^{46}$ If clustering is ignored, a "unit of analysis error" can occur, ${ }^{47}$ which will overestimate the effect of the intervention in the study, and also mean the study's weight in the meta-analysis is artificially high.

\section{Patient and public involvement}

This was a network meta-analysis of previously published randomised controlled trials. It was not possible for us to involve patients or the public in defining the research question, the design, or the evaluation and discussion of our work. We will disseminate our findings in lay terms through the national charity for people living with digestive diseases, "Guts UK."

\section{Results}

The search strategy generated 8781 citations, 59 of which we retrieved for further assessment because they appeared to be relevant (supplementary fig 4). Of these, 44 were excluded for various reasons, which left 15 eligible randomised controlled trials that comprised 6162 participants. Fourteen trials were fully published, ${ }^{13-184548-54}$ and data from another trial were available from a previous individual patient data meta-analysis conducted by our group. ${ }^{19}$ Agreement between investigators for trial eligibility was excellent ( $\kappa$ statistic $=0.91$ ). Supplementary table 1 reports risk of bias items for all included trials. Because the trials were all pragmatic, with blinding of participants impossible because of the differences in the strategies used, none was at low risk of bias.

Table 2 presents detailed characteristics of individual randomised controlled trials and the comparisons made. Six randomised controlled trials compared prompt endoscopy with "test and treat"17 19 48-51; three "test and treat" with empirical acid suppression $^{1445}{ }^{52}$; two prompt endoscopy with empirical acid suppression ${ }^{13}{ }^{53}$; one prompt endoscopy with symptom based management ${ }^{15}$; one "test and scope" with symptom based management ${ }^{16}$; one prompt endoscopy with empirical acid suppression or symptom based management ${ }^{54}$; and one prompt endoscopy with "test and scope," “test and treat," or empirical acid 


\begin{tabular}{|c|c|c|c|}
\hline Study & $\begin{array}{l}\text { Country, setting, and } \\
\text { duration of follow-up }\end{array}$ & $\begin{array}{l}\text { Characteristics of included } \\
\text { participants }\end{array}$ & No of participants in each trial arm and management strategies used \\
\hline Bytzer $1994^{13}$ & $\begin{array}{l}\text { Denmark, primary care, } \\
12 \text { months }\end{array}$ & $\begin{array}{l}414 \text { participants } \geq 18 \text { years, mean } \\
\text { age } 44 \text { years, } 238(57.5 \%) \text { female }\end{array}$ & $\begin{array}{l}208 \text { participants prompt endoscopy with medical treatment according to endoscopic findings; } \\
206 \text { participants empirical acid suppression using ranitidine } 150 \mathrm{mg} \text { twice daily for four weeks }\end{array}$ \\
\hline Heaney $1999^{48}$ & $\begin{array}{l}\text { Northern Ireland, } \\
\text { secondary care,* }^{*} \text { months }^{2}\end{array}$ & $\begin{array}{l}104 \text { participants } \geq 18-45 \text { years, } \\
\text { mean age } 32 \text { years, } 45(43.3 \%) \\
\text { female, } 104(100 \%) \text { Helicobacter } \\
\text { pylori positive }\end{array}$ & $\begin{array}{l}52 \text { participants prompt endoscopy with medical treatment according to endoscopic findings; } \\
52 \text { participants "test and treat" by carbon } 13 \text { urea breath test, with those testing positive receiving } \\
\text { eradication treatment with one week of omeprazole } 20 \mathrm{mg} \text { twice daily, clarithromycin } 250 \mathrm{mg} \text { twice } \\
\text { daily, and tinidazole } 500 \mathrm{mg} \text { twice daily }\end{array}$ \\
\hline Delaney $2000^{15}$ & $\begin{array}{l}\text { England, primary care, } \\
18 \text { months }\end{array}$ & $\begin{array}{l}442 \text { participants } \geq 50 \text { years, mean } \\
\text { age } 65 \text { years, } 222(50.7 \%) \text { female }\end{array}$ & $\begin{array}{l}256 \text { participants prompt endoscopy with medical treatment according to endoscopic findings; } \\
186 \text { participants symptom based management according to the primary care physician's preferred } \\
\text { strategy }\end{array}$ \\
\hline Lassen $2000^{49}$ & $\begin{array}{l}\text { Denmark, secondary } \\
\text { care, }^{\star} 12 \text { months }\end{array}$ & $\begin{array}{l}500 \text { participants } \geq 18 \text { years, mean } \\
\text { age } 46 \text { years, } 270(54.0 \%) \text { female, } \\
141(28.2 \%) H \text { pylori positive }\end{array}$ & $\begin{array}{l}250 \text { participants prompt endoscopy with medical treatment according to endoscopic findings; } \\
250 \text { participants "test and treat" by carbon } 13 \text { urea breath test, with those testing positive } \\
\text { receiving eradication treatment with two weeks of lansoprazole } 30 \mathrm{mg} \text { twice daily, metronidazole } \\
500 \mathrm{mg} \text { three times daily, and amoxicillin } 1 \mathrm{~g} \text { twice daily; those testing negative received } \\
\text { reassurance and lifestyle advice }\end{array}$ \\
\hline Delaney $2001^{16}$ & $\begin{array}{l}\text { England, primary care, } \\
18 \text { months }\end{array}$ & $\begin{array}{l}478 \text { participants } \geq 18-49 \text { years, } \\
\text { mean age } 37 \text { years, } 204(42.9 \%) \\
\text { female, } 112(40.3 \%) \text { of } 278 \text { in } \\
\text { "test and scope" arm } H \text { pylori } \\
\text { positive }\end{array}$ & $\begin{array}{l}285 \text { participants "test and scope" by serology, with endoscopy for } H \text { pylori positive participants and } \\
\text { medical treatment according to endoscopic findings; those testing negative received empirical acid } \\
\text { suppression; } \\
193 \text { participants symptom based management according to the primary care physician's preferred } \\
\text { strategy }\end{array}$ \\
\hline $\begin{array}{l}\text { Lewin van den } \\
\text { Broek } 2001^{54}\end{array}$ & $\begin{array}{l}\text { The Netherlands, } \\
\text { primary care, } \\
12 \text { months }\end{array}$ & $\begin{array}{l}265 \text { participants } \geq 18 \text { years, mean } \\
\text { age } 43.5 \text { years, } 113(45.9 \%) \text { of } \\
246 \text { with data female }\end{array}$ & $\begin{array}{l}86 \text { participants prompt endoscopy with medical treatment according to endoscopic findings; } \\
89 \text { participants empirical acid suppression using omeprazole } 20 \text { mg once daily for up to eight weeks; } \\
90 \text { participants symptom based management according to national primary care guidelines }\end{array}$ \\
\hline McColl $2002^{17}$ & $\begin{array}{l}\text { Scotland, secondary } \\
\text { care, }^{\star} 12 \text { months }\end{array}$ & $\begin{array}{l}708 \text { participants } \geq 18-55 \text { years, } \\
\text { mean age } 36 \text { years, } 331(46.8 \%) \\
\text { female, } 352(49.7 \%) H \text { pylori } \\
\text { positive }\end{array}$ & $\begin{array}{l}352 \text { participants prompt endoscopy; also tested for } \mathrm{H} \text { pylori by carbon } 14 \text { urea breath test, with } \\
\text { those testing positive receiving eradication treatment as described below; } \\
356 \text { participants “test and treat" by carbon } 14 \text { urea breath test, with those testing positive receiv- } \\
\text { ing eradication treatment with one week of omeprazole } 20 \mathrm{mg} \text { twice daily, clarithromycin } 250 \mathrm{mg} \\
\text { three times daily, and amoxicillin } 500 \mathrm{mg} \text { or metronidazole } 400 \mathrm{mg} \text { three times daily; those testing } \\
\text { negative received reassurance }\end{array}$ \\
\hline Arents $2003^{50}$ & $\begin{array}{l}\text { The Netherlands, } \\
\text { primary care, } \\
12 \text { months }\end{array}$ & $\begin{array}{l}270 \text { participants } \geq 18 \text { years, mean } \\
\text { age } 44 \text { years, } 141(52.2 \%) \text { female, } \\
102(37.8 \%) \text { H pylori positive }\end{array}$ & $\begin{array}{l}129 \text { participants prompt endoscopy with medical treatment according to endoscopic findings; } \\
\text { also tested for } H \text { pylori by serology, with those testing positive receiving eradication treatment, as } \\
\text { described below; } \\
141 \text { participants “test and treat" by serology, with those testing positive receiving eradication } \\
\text { treatment with one week of lansoprazole } 30 \mathrm{mg} \text { twice daily, amoxicillin } 1 \mathrm{~g} \text { twice daily, and } \\
\text { metronidazole or clarithromycin } 500 \mathrm{mg} \text { twice daily; those testing negative received cisapride } 20 \\
\text { mg twice daily for four weeks }\end{array}$ \\
\hline Manes $2003^{52}$ & $\begin{array}{l}\text { Italy, secondary care, } \\
12 \text { months }\end{array}$ & $\begin{array}{l}219 \text { participants } \geq 18-45 \text { years, } \\
\text { mean age } 38.5 \text { years, } 99(45.2 \%) \\
\text { female, } 67(60.9 \%) \text { of } 110 \text { in "test } \\
\text { and treat" arm } H \text { pylori positive }\end{array}$ & $\begin{array}{l}110 \text { participants "test and treat" by carbon } 13 \text { urea breath test, with those testing positive } \\
\text { receiving eradication treatment with one week of omeprazole } 20 \text { mg twice daily, clarithromycin } \\
500 \mathrm{mg} \text { twice daily, and tinidazole } 500 \mathrm{mg} \text { twice daily; those testing negative received omeprazole } \\
20 \mathrm{mg} \text { once daily for four weeks; } \\
109 \text { participants empirical acid suppression using omeprazole } 20 \mathrm{mg} \text { once daily for four weeks }\end{array}$ \\
\hline Jarbol $2006^{45}$ & $\begin{array}{l}\text { Denmark, primary care, } \\
12 \text { months }\end{array}$ & $\begin{array}{l}472 \text { participants } \geq 18 \text { years, mean } \\
\text { age } 45.4 \text { years, } 272(57.6 \%) \\
\text { female, } 60 \text { ( } 24.0 \%) \text { of } 250 \text { in "test } \\
\text { and treat" arm } \mathrm{H} \text { pylori positive }\end{array}$ & $\begin{array}{l}250 \text { participants "test and treat" by carbon } 13 \text { urea breath test, with those testing positive } \\
\text { receiving eradication treatment with one week of esomeprazole } 20 \mathrm{mg} \text { twice daily, clarithromycin } \\
500 \mathrm{mg} \text { twice daily, and amoxicillin } 1 \mathrm{~g} \text { twice daily; those testing negative received no treatment; } \\
222 \text { participants empirical acid suppression using esomeprazole } 20 \mathrm{mg} \text { twice daily for one week }\end{array}$ \\
\hline Kjeldsen $2007^{53}$ & $\begin{array}{l}\text { Denmark, primary care, } \\
12 \text { months }\end{array}$ & $\begin{array}{l}368 \text { participants } \geq 18 \text { years, mean } \\
\text { age } 48 \text { years, } 202(54.9 \%) \text { female }\end{array}$ & $\begin{array}{l}184 \text { participants prompt endoscopy with medical treatment according to endoscopic findings; } \\
184 \text { participants empirical acid suppression using omeprazole } 40 \mathrm{mg} \text { once daily for two weeks }\end{array}$ \\
\hline Delaney $2008^{14}$ & $\begin{array}{l}\text { England, primary care, } \\
12 \text { months }\end{array}$ & $\begin{array}{l}699 \text { participants } \geq 18-65 \text { years, } \\
\text { mean age } 41 \text { years, } 355(50.8 \%) \\
\text { female, } 100(29.2 \%) \text { of } 343 \\
\text { in “test and treat" arm } H \text { pylori } \\
\text { positive }\end{array}$ & $\begin{array}{l}343 \text { participants "test and treat" by carbon } 13 \text { urea breath test, with those testing positive } \\
\text { receiving eradication treatment with one week of omeprazole } 20 \mathrm{mg} \text { once daily, clarithromycin } 250 \\
\text { mg twice daily, and metronidazole } 400 \mathrm{mg} \text { twice daily; those testing negative received omeprazole } \\
20 \mathrm{mg} \text { once daily for four weeks; } \\
356 \text { participants empirical acid suppression using omeprazole } 20 \mathrm{mg} \text { once daily for four weeks }\end{array}$ \\
\hline Mahadeva $2008^{51}$ & $\begin{array}{l}\text { Malaysia, secondary } \\
\text { care, }^{\star} 12 \text { months }\end{array}$ & $\begin{array}{l}432 \text { participants } \geq 18-45 \text { years, } \\
\text { mean age } 30.5 \text { years, } 234(54.2 \%) \\
\text { female, } 141(32.6 \%) \mathrm{H} \text { pylori } \\
\text { positive }\end{array}$ & $\begin{array}{l}210 \text { participants prompt endoscopy with medical treatment according to endoscopic findings; also } \\
\text { tested for } \mathrm{H} \text { pylori by rapid urease test, with those testing positive receiving eradication treatment, } \\
\text { as described below; } \\
222 \text { participants "test and treat" by carbon } 13 \text { urea breath test, with those testing positive } \\
\text { receiving eradication treatment with one week of pantoprazole } 40 \mathrm{mg} \text { twice daily, clarithromycin } \\
500 \mathrm{mg} \text { twice daily, and amoxicillin } 1 \mathrm{~g} \text { twice daily; those testing negative received reassurance and } \\
\text { symptom based treatment }\end{array}$ \\
\hline Duggan $2009^{18}$ & $\begin{array}{l}\text { England, primary care, } \\
12 \text { months }\end{array}$ & $\begin{array}{l}762 \text { participants } \geq 18-70 \text { years, } \\
\text { mean age } 42 \text { years, } 351(46.1 \%) \\
\text { female, } 277(36.4 \%) \text { H pylori } \\
\text { positive }\end{array}$ & $\begin{array}{l}187 \text { participants prompt endoscopy with medical treatment according to endoscopic findings; } \\
199 \text { participants "test and scope" by serology, with endoscopy for } \mathrm{H} \text { pylori positive participants and } \\
\text { medical treatment according to endoscopic findings; those testing negative received lansoprazole } \\
30 \mathrm{mg} \text { once daily for four weeks; } \\
198 \text { participants "test and treat" by serology, with those testing positive receiving eradication } \\
\text { treatment with one week of omeprazole } 20 \mathrm{mg} \text { twice daily, clarithromycin } 250 \mathrm{mg} \text { twice daily, and } \\
\text { metronidazole } 400 \mathrm{mg} \text { twice daily; those testing negative received lansoprazole } 30 \mathrm{mg} \text { once daily } \\
\text { for four weeks; } \\
178 \text { participants empirical acid suppression using lansoprazole } 30 \text { mg once daily for four weeks }\end{array}$ \\
\hline $\begin{array}{l}\text { Myres (unpub- } \\
\text { lished) † }\end{array}$ & $\begin{array}{l}\text { Wales, primary care, } \\
12 \text { months }\end{array}$ & $\begin{array}{l}61 \text { participants } \geq 18-45 \text { years, } \\
\text { mean age } 34 \text { years, } 33(54.1 \%) \\
\text { female, } 61(100 \%) \text { H pylori } \\
\text { positive }\end{array}$ & $\begin{array}{l}28 \text { participants prompt endoscopy with medical treatment according to endoscopic findings; } \\
33 \text { participants "test and treat" by serology, with those testing positive receiving eradication } \\
\text { treatment according to the primary care physician's preferred strategy for treatment of } H \text { pylori }\end{array}$ \\
\hline
\end{tabular}


suppression. ${ }^{18}$ Direct evidence was therefore available for nine of the 10 possible comparisons. All trials were of 12 months' duration, with the exception of two randomised controlled trials in which the final point of follow-up was 18 months. ${ }^{1516}$

\section{Effectiveness}

Intention to treat analysis

All 15 randomised controlled trials provided dichotomous data for likelihood of remaining symptomatic at the final point of follow-up. $.^{13-1945} 48-54$ In these 15 trials, 1942 participants were randomised to prompt endoscopy, 484 to "test and scope," 1938 to "test and treat," 1329 to empirical acid suppression, and 469 to symptom based management. Figure 1 presents the network plot. When data were pooled, there was little observed heterogeneity $\left(\tau^{2}=0.007\right)$, and no evidence of publication bias or other small study effects (supplementary fig 5). Of the five strategies, "test and treat" was ranked first (relative risk of remaining symptomatic 0.89 , 95\% confidence interval 0.78 to 1.02, P score 0.79; fig 2). The network heat plot had no red "hotspots" of inconsistency (supplementary fig 6), and there was no evidence of inconsistency under the full design by treatment interaction model after applying the $\chi^{2}$ test of the $\mathrm{Q}$ statistic (1.91, $\mathrm{P}=0.93$ ). The netsplit analysis did not identify any significant differences between the direct and indirect treatment effect estimates for any of the treatment comparisons (supplementary table 2). None of the strategies was significantly less effective than "test and treat," or more effective than each other, on either direct or indirect comparison (fig 3). Prompt endoscopy was ranked second, but performed similarly to "test and treat" (relative risk of remaining symptomatic 0.90, 95\% confidence interval 0.80 to 1.02 , P score 0.71 ). This means that the probability of "test and treat" or prompt endoscopy being the most effective strategy when all five management strategies, including symptom based management, were compared with each other was $79 \%$ and $71 \%$, respectively. In contrast, the probability of "test and scope," empirical acid suppression, or symptom based management being the most effective strategy was $57 \%, 30 \%$, and $12 \%$, respectively.

Two of the trials of "test and treat" versus prompt endoscopy recruited only participants with $H$ pylori infection, ${ }^{1948}$ and one of the trials of prompt endoscopy versus empirical acid suppression used ranitidine, ${ }^{13}$ rather than a proton pump inhibitor. Therefore, we excluded these three trials in a retrospective sensitivity analysis so as not to overestimate the effectiveness of "test and treat," or underestimate the effectiveness of empirical acid suppression. When data were pooled, there was little observed heterogeneity $\left(\tau^{2}=0.007\right)$. “Test and treat" was ranked first (relative risk 0.89, $95 \%$ confidence interval 0.77 to 1.02 , P score 0.82 ) and prompt endoscopy second $(0.90,0.79$ to 1.02 , $\mathrm{P}$ score 0.70$)$. When we excluded the two trials of 18 months' duration, the overall results were not affected $^{15}{ }^{16}$; "test and treat" was still ranked first and prompt endoscopy second.

\section{Per protocol analysis}

All 15 randomised controlled trials provided dichotomous data for likelihood of remaining symptomatic at the final point of follow-up according to a per protocol analysis. ${ }^{13-19} 45$ 48-54 In this analysis, there were data on 5154 participants, of whom 1667 were randomised to prompt endoscopy, 326 to "test and scope," 1689 to "test and treat," 1150 to empirical acid suppression, and 322 to symptom based management. Supplementary fig 7 presents the network plot. Again, when data were pooled, there was little observed heterogeneity $\left(\tau^{2}=0.009\right)$, and no evidence of publication bias or other small study effects (supplementary fig 8). There were no red "hotspots" of inconsistency on the network heat plot (supplementary fig 9), with no evidence of inconsistency under the full design by treatment interaction model after applying the $\chi^{2}$ test of the $\mathrm{Q}$ statistic $(1.28, \mathrm{P}=0.97)$. The netsplit analysis did not identify any significant differences between the direct and indirect treatment effect estimates for any of the treatment comparisons (supplementary table 3). Once again, "test and treat" was ranked first (relative risk 0.87, 95\% confidence interval 0.74 to 1.03 , P score 0.79 ; supplementary fig 10), but was not superior to any of the other four strategies, and none of the strategies was more effective than any of the others on direct or indirect comparison (supplementary table 4). The P scores for prompt endoscopy, "test and scope," empirical acid suppression, or symptom based management were $0.69,0.63,0.26$, and 0.13 , respectively. As before, when we excluded the three aforementioned trials in a retrospective sensitivity analysis, ${ }^{13} 1948$ there was little observed heterogeneity $\left(\tau^{2}=0.007\right)$, and "test and treat" was ranked first (relative risk 0.87, 95\% confidence interval 0.73 to 1.02 , P score 0.81 ), with prompt endoscopy second (0.88, 0.76 to 1.03 , P score 0.68). Again, excluding the two trials of 18 months' duration did not affect the overall results ${ }^{15}{ }^{16}$; "test and treat" was still ranked first and prompt endoscopy second.

\section{Rates of endoscopy}

Fourteen randomised controlled trials that comprised 5897 participants, provided data on the number of participants in each arm undergoing endoscopy. ${ }^{13-19} 45$ 48-53 Supplementary fig 11 presents the network plot. When data were pooled, there was a moderate level of statistical heterogeneity $\left(\tau^{2}=0.16\right)$, but no evidence of publication bias or other small study effects (supplementary fig 12). The network heat plot had no red "hotspots" of inconsistency (supplementary fig 13), and there was no evidence of inconsistency under the full design by treatment interaction model after we applied the $\chi^{2}$ test of the $\mathrm{Q}$ statistic $(2.56, \mathrm{P}=0.63)$. The netsplit analysis did not identify any significant differences between the direct and indirect treatment effect estimates for any of the treatment comparisons (supplementary table 5). Of the five strategies, "test and treat" was ranked first (relative risk of receiving endoscopy $0.23,95 \%$ confidence interval 0.17 to 


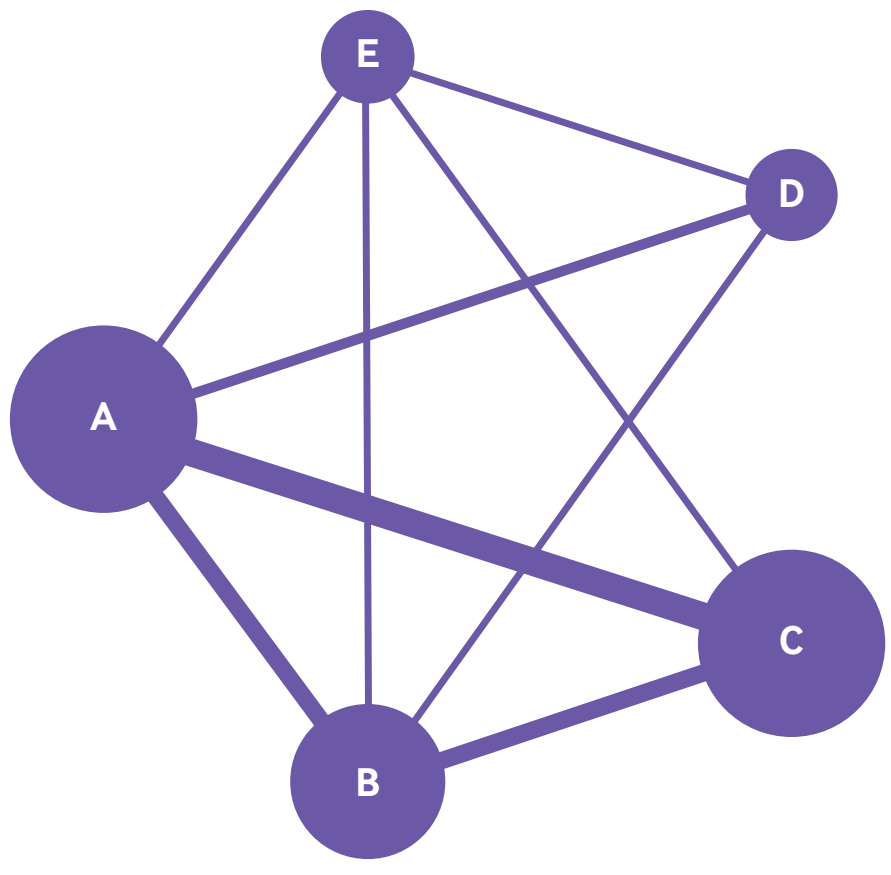

Intervention
Prompt endoscopy
Empirical acid suppression
"Test and treat"
Symptom based management
"Test and scope"

$\begin{array}{ccc}\text { Abbreviation } & \begin{array}{c}\text { Number of } \\ \text { trial arms }\end{array} & \begin{array}{c}\text { Number of } \\ \text { participants }\end{array} \\ \text { A } & 11 & 1942 \\ \text { B } & 7 & 1329 \\ \text { C } & 10 & 1938 \\ \text { D } & 3 & 469 \\ \text { E } & 2 & 484\end{array}$

Fig 1 | Network plot for likelihood of remaining symptomatic according to intention to treat analysis at final point of follow-up suppression were significantly less likely to receive endoscopy than those assigned to prompt endoscopy.

\section{Participant dissatisfaction with management}

Only six trials that comprised 2818 participants reported rates of satisfaction with management according to strategy ${ }^{13} 18{ }^{45}{ }^{49-51}$; no randomised controlled trials reported on satisfaction with symptom based management. Supplementary fig 14 presents the network plot. The term "risk" has negative connotations; therefore, in this analysis, we chose to extract data as rates of dissatisfaction with management, such that the best performing strategy has the lowest risk of dissatisfaction (rather than the highest risk of being satisfied). When data were pooled, there was a moderate level of statistical heterogeneity $\left(\tau^{2}=0.13\right)$, and too few randomised controlled trials to assess for evidence of publication bias, or other small study effects. Of the four strategies, prompt endoscopy was ranked first (relative risk of being dissatisfied 0.58, 95\% confidence interval 0.37 to 0.91 , P score 0.95; supplementary fig 15). Participants allocated to prompt endoscopy were significantly less likely to be dissatisfied with management compared with participants randomised to "test and treat" or empirical acid suppression, on indirect comparison, and with empirical acid suppression on direct comparison (supplementary table 6). The netsplit analysis did not identify any significant differences between the direct and indirect treatment effect estimates for any of the treatment comparisons (supplementary table 7). However, the network heat plot revealed a red "hotspot" of potential inconsistency (supplementary fig 16), with evidence of inconsistency under the full design by treatment interaction model after applying the $\chi^{2}$ test of the $\mathrm{Q}$ statistic $(26.07, \mathrm{P}<0.001)$. This was driven by one early study of prompt endoscopy versus empirical acid suppression, ${ }^{13}$ which showed substantially higher rates of dissatisfaction with empirical acid suppression. Rerunning the network without this trial resolved the inconsistency ( $Q$ statistic 1.73, $\mathrm{P}=0.42)$ and reduced heterogeneity $\left(\tau^{2}=0.002\right)$, but did not change the ranking of prompt endoscopy (relative risk 0.85, 95\% confidence interval 0.70 to 1.02, P score 0.97).
0.31, P score 0.98; fig 4). When we performed an indirect comparison we found participants allocated to "test and treat" were significantly less likely to receive endoscopy than those in any of the other management strategies, except symptom based management. Participants assigned to all four other strategies were significantly less likely to receive endoscopy than those randomised to prompt endoscopy (fig 5). When we performed a direct comparison, we found participants randomised to "test and treat" or empirical acid

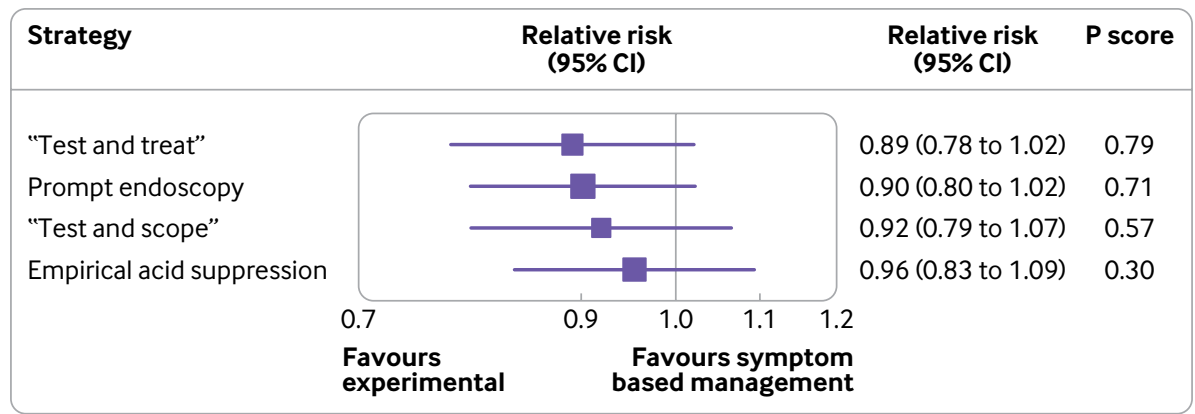

Fig 2 | Forest plot for likelihood of remaining symptomatic according to intention to treat analysis at final point of follow-up. $\mathrm{P}$ score is probability of each treatment being ranked as best in network analysis. Higher score indicates greater probability of being ranked first 


\begin{tabular}{|c|c|c|c|c|}
\hline “Test and treat" & 1.01 (0.93 to 1.10$)$ & 1.02 (0.81 to 1.28$)$ & $0.91(0.82$ to 1.01$)$ & NA \\
\hline $0.99(0.92$ to 1.07$)$ & $\begin{array}{c}\text { Prompt } \\
\text { endoscopy }\end{array}$ & $0.94(0.75$ to 1.19$)$ & $0.96(0.86$ to 1.08$)$ & $0.90(0.78$ to 1.05$)$ \\
\hline $0.97(0.83$ to 1.13$)$ & $0.98(0.84$ to 1.14$)$ & "Test and scope” & $0.99(0.79$ to 1.25$)$ & $0.92(0.76$ to 1.11$)$ \\
\hline $0.93(0.86$ to 1.01$)$ & $0.94(0.87$ to 1.03$)$ & $0.96(0.82$ to 1.12$)$ & $\begin{array}{c}\text { Empirical acid } \\
\text { suppression }\end{array}$ & 0.93 (0.75 to 1.16) \\
\hline $0.89(0.78$ to 1.02$)$ & $0.90(0.80$ to 1.02$)$ & $0.92(0.79$ to 1.07$)$ & $0.96(0.83$ to 1.09$)$ & $\begin{array}{c}\text { Symptom based } \\
\text { management }\end{array}$ \\
\hline
\end{tabular}

Fig 3 | Summary treatment effects from network meta-analysis for likelihood of remaining symptomatic according to intention to treat analysis at final point of follow-up. Comparisons, column versus row, should be read from left to right, and are ordered relative to overall effectiveness. Treatment in top left position is ranked as best after network meta-analysis of direct and indirect effects. Direct comparisons are provided above strategy labels, and indirect comparisons are below. Values are relative risk ( $95 \%$ confidence interval). $N A=$ not applicable, no randomised controlled trials making direct comparisons

Rates of upper gastrointestinal cancer detection Eleven randomised controlled trials reported upper gastrointestinal cancer detection rates among 5028 participants. ${ }^{13-18}$ 48-52 In total, $20(0.40 \%)$ cancers were detected: $11(0.67 \%)$ among 1644 participants undergoing prompt endoscopy; four (0.24\%) among 1672 participants allocated to "test and treat"; two (0.41\%) among 484 participants assigned to "test and scope"; two (0.24\%) among 849 participants randomised to empirical acid suppression; and one $(0.26 \%)$ among 379 participants given symptom based management. Cancer location and type were provided for 16 participants; gastric adenocarcinoma occurred in 12 people, gastric lymphoma in two people, and oesophageal carcinoma in two people. Both participants with oesophageal carcinoma had previously reported dysphagia, and arguably, were recruited inappropriately to the relevant trial. ${ }^{18}$

\section{Discussion}

\section{Principal findings}

This systematic review and network meta-analysis has shown that "test and treat" might be the most effective first line strategy for the management of uninvestigated dyspepsia in primary care, in terms of effect on symptoms, although prompt endoscopy performed similarly in this respect. However, no strategy was significantly less effective than "test and treat," or more effective than another strategy, on either direct or indirect comparison. "Test and treat" was significantly more likely to reduce use of endoscopy compared with all strategies, other than symptom based management. Despite this, rates of dissatisfaction with management were significantly lower among participants allocated to prompt endoscopy compared with "test and treat" or empirical acid suppression on indirect comparison. Finally, detection rates of upper gastrointestinal cancer in these trials were extremely low.

\section{Strengths and limitations of the study}

The network meta-analysis allowed us to make indirect comparisons among over 6000 participants in 15 randomised controlled trials. The trials themselves were pragmatic and recruited participants from primary care, or on first referral to secondary care, which meant the results of our study are likely to be generalisable to other patients who present with dyspepsia in this setting. We used the most stringent endpoint for effect on symptoms in all trials, and only classified participants who were completely asymptomatic as having reached the endpoint of interest. We used an intention to treat analysis, with all trial dropouts assumed to be symptomatic. Because of the length of follow-up in individual randomised controlled trials, we performed a sensitivity analysis by using a per protocol analysis. We also excluded

\begin{tabular}{|c|c|c|c|}
\hline Strategy & $\begin{array}{l}\text { Relative risk } \\
(95 \% \mathrm{Cl})\end{array}$ & $\begin{array}{l}\text { Relative risk } \\
\quad(95 \% \mathrm{Cl})\end{array}$ & P score \\
\hline \multirow{6}{*}{$\begin{array}{l}\text { "Test and treat" } \\
\text { Symptom based management } \\
\text { Empirical acid suppression } \\
\text { "Test and scope" }\end{array}$} & 2 & $0.23(0.17$ to 0.31$)$ & 0.98 \\
\hline & & $0.39(0.20$ to 0.74$)$ & 0.61 \\
\hline & & 0.39 (0.27 to 0.56$)$ & 0.59 \\
\hline & & 0.55 (0.30 to 0.99$)$ & 0.32 \\
\hline & 1.0 & & \\
\hline & $\begin{array}{r}\text { Favours prompt } \\
\text { endoscopy }\end{array}$ & & \\
\hline
\end{tabular}

Fig 4 | Forest plot for likelihood of receiving endoscopy. P score is probability of each treatment being ranked as best in network analysis. Higher score indicates greater probability of being ranked first 


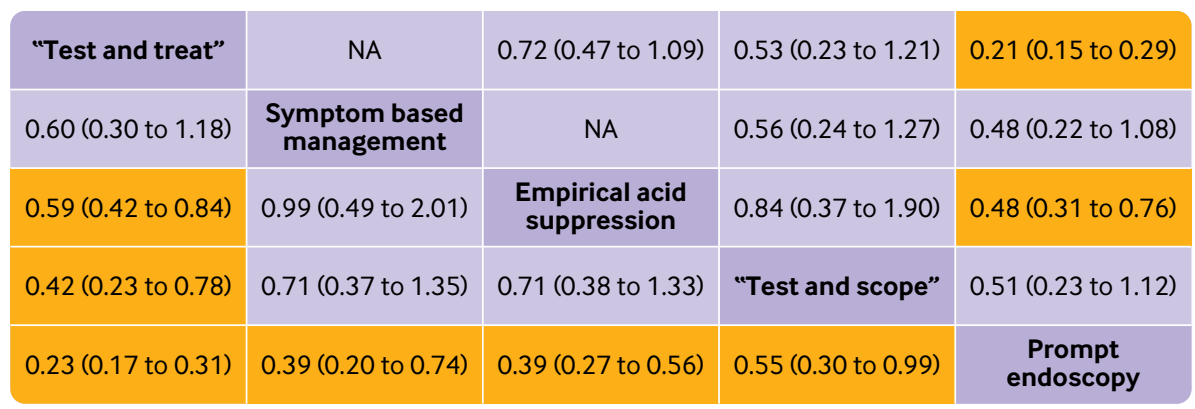

Fig 5 | Summary treatment effects from network meta-analysis for likelihood of receiving endoscopy. Comparisons, column versus row, should be read from left to right, and are ordered relative to overall effectiveness. Treatment in top left position is ranked as best after network meta-analysis of direct and indirect effects. Orange boxes indicate significant differences. Direct comparisons are provided above strategy labels, and indirect comparisons are below. Values are relative risk ( $95 \%$ confidence interval). $\mathrm{NA}=$ not applicable, no randomised controlled trials making direct comparisons

two randomised controlled trials that examined effectiveness of prompt endoscopy versus "test and treat" only in participants who were $H$ pylori positive $\mathrm{e}^{19} 48$ and one that used empirical ranitidine as an acid suppressant ${ }^{13}$ in a separate retrospective sensitivity analysis. Our findings remained unchanged in this analysis. Finally, we produced network heat plots and identified inconsistency in one of our analyses, but this was resolved when we excluded one study that reported a large difference in dissatisfaction rates between prompt endoscopy and empirical acid suppression.

Our study had several limitations. We did not have access to individual patient data for the network meta-analysis, which meant that we were unable to study the effects of the various management strategies on other dyspepsia related resource use, or total costs of managing dyspepsia. There were also differences between individual trials in the population studied, study setting, the way the intervention was applied, duration of follow-up, and endpoint used to define symptom response; therefore, it might not be appropriate to combine data from these trials in a meta-analysis. However, we only classed those as entirely asymptomatic as having reached the endpoint of interest, and we performed sensitivity analyses based on some of these study characteristics, and our results were unchanged. These differences could explain the moderate amounts of heterogeneity in some of our analyses.

Additionally, only six randomised controlled trials contributed data to the analysis of dissatisfaction with management, ${ }^{13} 184549-51$ and four of these compared prompt endoscopy with "test and treat,"18 49-51 which meant that the findings from this analysis might not be as robust for the other strategies. We were not able to examine the effect of these management strategies on quality of life in the network meta-analysis because the included studies used a variety of instruments, disease specific and generic; they also reported these analyses in a multitude of ways, which precluded pooling of the data. Because most studies were conducted in western populations, with only one randomised controlled trial conducted in Malaysia, ${ }^{51}$ our findings cannot be extrapolated to the Far East where the incidence of gastric cancer is higher, and prompt endoscopy might therefore be more appropriate. Finally, all of the included randomised controlled trials were at high risk of bias because of their pragmatic design, which meant that blinding of participants was not possible.

\section{Comparison with other studies}

We believe this network meta-analysis is an advance over previous meta-analyses in this field for several reasons. Our meta-analysis produces a credible ranking system for each strategy, rather than relying on summary relative risks of comparative effectiveness of one strategy over another. This approach is clinically useful given that in previous individual patient data meta-analyses there was only a small, although statistically significant, difference in the relative risk of remaining symptomatic, which favoured prompt endoscopy over "test and treat." ${ }^{19}$ Additionally, no difference was found between "test and treat" and empirical acid suppression. ${ }^{22}$ Furthermore, more randomised controlled trials have been included in our analysis than in the aforementioned individual patient data meta-analyses, ${ }^{19}{ }^{22}$ and a previous trial based meta-analysis. ${ }^{55}$ Our meta-analysis was also able to make indirect and direct comparisons by using trial data, which led to a change in the strategy that could be the most effective for first line management of uninvestigated dyspepsia. "Test and treat" was ranked above prompt endoscopy, although $\mathrm{P}$ scores were similar. Additionally, the equipoise between "test and treat" and empirical acid suppression was no longer seen, with a $\mathrm{P}$ score for "test and treat" of 0.79 compared with 0.30 for empirical acid suppression. Although National Institute for Health and Care Excellence guidance states that either "test and treat" or empirical acid suppression can be used first line for uninvestigated dyspepsia, ${ }^{21}$ the "test and treat" strategy was recommended first line for patients younger than 60 by the more recent American College of Gastroenterology and Canadian Association of Gastroenterology joint practice guideline on 
dyspepsia. ${ }^{20}$ The results of our network meta-analysis support the latter recommendation. Finally, a previous trial based meta-analysis combined participants in the empirical acid suppression and symptom based management arms. ${ }^{55}$ Because those receiving symptom based management did not receive standardised proton pump inhibitor dosing in these randomised controlled trials, we believe this is technically incorrect, and might have led to an underestimate of the effectiveness of empirical acid suppression.

Dyspepsia, however defined, is a frequent reason for consultation with primary care providers and gastroenterologists. Dyspeptic symptoms can cause substantial anxiety for patients who might fear that they have a serious underlying condition to account for their symptoms. This anxiety is despite the fact that upper gastrointestinal malignancy is identified at endoscopy in less than $1 \%$ of patients. ${ }^{56}$ Of note, the rate of upper gastrointestinal malignancy in this metaanalysis was only around $0.4 \%$, which suggests that, among 1000 patients presenting to a primary care provider with uninvestigated dyspepsia, 996 would be cancer free on endoscopy. This makes the strategy of prompt endoscopy for the evaluation of uninvestigated dyspepsia highly questionable, at least in the absence of potentially important alarm features that, arguably, would merit endoscopy in any case. A previous study in the USA estimated that the cost of detecting one upper gastrointestinal cancer in patients aged 50 or older with dyspepsia without alarm features in primary care was over $\$ 80000$ ( $€ 62000$; €72 300). ${ }^{57}$ Prompt endoscopy might be justifiable on the basis of providing reassurance to patients about the absence of a sinister underlying cause of their symptoms, but studies suggest this effect is relatively short lived. ${ }^{58}$ Although "test and treat" was ranked first in terms of effectiveness, and significantly limited the use of endoscopy, we found lower levels of dissatisfaction with management among participants randomised to prompt endoscopy. Given the lack of blinding in all of the included studies, this could relate to patients' previous expectations of management, which were not met if assigned to a non-invasive management strategy; patients might prefer endoscopy for what they consider to be a more thorough and appropriate evaluation of their symptoms. Furthermore, the impact of negative findings at endoscopy probably also influences patients' satisfaction with this approach.

We must weigh these potential benefits of endoscopy against its substantial costs and the risk of adverse events, albeit small. Because endoscopy is the principal driver of overall costs in the management of dyspepsia, it cannot be supported based on cost effectiveness. This consideration is underlined by a previous individual patient data meta-analysis of prompt endoscopy versus "test and treat," 19 which estimated that prompt endoscopy was only cost effective if the willingness to pay per patient cured of their dyspepsia was $\$ 180000$. Endoscopy can identify $H$ pylori infection, although it is not essential for that purpose because there are widely available, cheaper, non-invasive tests for active infection with excellent performance characteristics. However, the American Gastroenterological Association has recommended routine collection of gastric biopsies at endoscopy when performed in patients with dyspepsia to document the presence or absence of $H$ pylori infection ${ }^{59}$; however, treatment of the infection leads to sustained symptom improvement in only a minority of patients. ${ }^{60}$

\section{Conclusions and policy implications}

The strategy of "test and treat" has proved popular in many countries. $H$ pylori infection is usually asymptomatic, but it can lead to dyspepsia even in the absence of peptic ulcer disease. ${ }^{61}$ The non-invasive detection of $H$ pylori infection with a reliable test, such as the urea breath test or faecal antigen test, should lead automatically to treatment for the infection. The "test and treat" strategy would detect most patients with dyspepsia and underlying peptic ulcer disease, although it would not identify them individually; they would certainly benefit from eradication of the infection. However, most patients with $H$ pylori infection would not have peptic ulcer disease and many would fulfil diagnostic criteria for functional dyspepsia. Eradication of the infection would produce sustained improvement in only a minority of these patients, but it would remove a potentially serious cause of disease in the remainder. Population screening and treatment for $H$ pylori appears to reduce future dyspepsia related costs in the West, ${ }^{62}$ and also reduces incidence of gastric cancer in high risk populations, ${ }^{63}$ so there are probably other benefits from more widespread use of "test and treat." That said, many of the trials included in the network meta-analysis were conducted more than 15 years ago, and the prevalence of $H$ pylori infection might have declined in Western populations during this time. A simulation model of the cost effectiveness of management strategies for uninvestigated dyspepsia in the USA suggested that "test and treat" was unlikely to remain cost effective below a prevalence of infection of $20 \%$, although the confidence intervals were wide. ${ }^{64}$

Symptom based management was ranked the lowest of all the strategies when considering effectiveness. Management of dyspepsia with drug treatments is unsatisfactory and often lacks an adequate evidence base because the underlying causes of symptoms are poorly understood. This makes targeted drug interventions empirical at best. Patients with dyspepsia might be treated with a variety of drugs, depending on local availability and approval, physicians' personal experience, and to some extent, on assessment of an individual patient's symptom profile. Recent guidelines recommend the use of empirical proton pump inhibitor treatment for patients younger than 60 in whom "test and treat" is unsuccessful and in those without $H$ pylori infection. ${ }^{20}$ Although acid suppression with a proton pump inhibitor might be effective for some patients, ${ }^{65}$ their long term efficacy is unclear and the optimal duration of treatment is not defined. In patients whose dyspeptic symptoms do not 
respond to a proton pump inhibitor, there is no value in continuing with this treatment. Furthermore, recent concerns about the long term safety of these drugs, although often based on weak evidence, ${ }^{66}$ could have altered perceptions of their appropriateness for the long term management of dyspepsia. Additional drug interventions that could be used for the management of dyspepsia include drugs with presumed prokinetic effects $^{67}$ and neuromodulators, including tricyclic antidepressants. ${ }^{68}$ The role of prokinetic agents is limited because of their lack of availability in many countries. Neuromodulators have an important role in the management of dyspepsia and other functional gastrointestinal disorders. ${ }^{68-70}$ However, the decision to use any of these drugs, and the order in which they might be tried, is based on choices made by individual physicians and patients, and to some extent is influenced by the factors listed here. Therefore, it is perhaps unsurprising that this largely empirical strategy was the least effective.

In summary, dyspepsia continues to be a highly prevalent condition that can influence quality of life profoundly and accounts for major healthcare expenditures. Many different management strategies have been studied in individual randomised controlled trials. This network meta-analysis provides additional support for the so called "test and treat" approach in management. This strategy, recently recommended in national guidelines, ${ }^{20}$ was consistently associated with the lowest chance of remaining symptomatic and with the lowest use of endoscopy. Therefore, it is probably of benefit in reducing overall costs, at least in some healthcare delivery models. However, despite the low diagnostic yield of endoscopy in detecting upper gastrointestinal tract malignancy, it might be the strategy most preferred by patients. Management of patients with dyspepsia should continue to be based on best evidence, but should also take into account the nuances of the individual patient within the confines of the healthcare setting.

Contributors: $\mathrm{LHE}, \mathrm{CJB}, \mathrm{CWH}$, and ACF conceived and drafted the study. $\mathrm{LHE}, \mathrm{CJB}, \mathrm{CWH}$, and ACF analysed and interpreted the data. ACF drafted the manuscript. LHE and CJB contributed equally to the manuscript and are joint first authors. All authors have approved the final draft of the manuscript. ACF is guarantor. ACF accepts full responsibility for the work and the conduct of the study, had access to the data, and controlled the decision to publish. The corresponding author attests that all listed authors meet authorship criteria and that no others meeting the criteria have been omitted.

Funding: No funding given.

Competing interests: All authors have completed the ICMJE uniform disclosure form at www.icmje.org/coi_disclosure.pdf and declare: no support from any organisation for the submitted work; no financial relationships with any organisations that might have an interest in the submitted work in the previous three years; no other relationships or activities that could appear to have influenced the submitted work.

Ethical approval: Ethical approval for this evidence synthesis was not required.

Data sharing: No additional data available.

The lead author (ACF) affirms that the manuscript is an honest, accurate, and transparent account of the study being reported; that no important aspects of the study have been omitted; and that any discrepancies from the study as originally planned (and, if relevant, registered) have been explained.
This is an Open Access article distributed in accordance with the Creative Commons Attribution Non Commercial (CC BY-NC 4.0) license, which permits others to distribute, remix, adapt, build upon this work non-commercially, and license their derivative works on different terms, provided the original work is properly cited and the use is noncommercial. See: http://creativecommons.org/licenses/by-nc/4.0/.

1 Ford AC, Marwaha A, Sood R, Moayyedi P. Global prevalence of, and risk factors for, uninvestigated dyspepsia: a meta-analysis. Gut 2015;64:1049-57. doi:10.1136/gutjnl-2014-307843

2 Ford AC, Forman D, Bailey AG, Axon AT, Moayyedi P. Effect of dyspepsia on survival: a longitudinal 10-year follow-up study. Am J Gastroenterol 2012;107:912-21. doi:10.1038/ajg.2012.69

3 Chang JY, Locke GR3rd, McNally MA, et al. Impact of functiona gastrointestinal disorders on survival in the community. Am J Gastroenterol 2010;105:822-32. doi:10.1038/ajg.2010.40

4 Ford AC, Forman D, Bailey AG, Axon AT, Moayyedi P. Initial poor quality of life and new onset of dyspepsia: results from a longitudinal 10-year follow-up study. Gut 2007;56:321-7. doi:10.1136/ gut.2006.099846

5 Agréus L, Svärdsudd K, Talley NJ, Jones MP, Tibblin G. Natural history of gastroesophageal reflux disease and functional abdominal disorders: a population-based study. Am J Gastroenterol 2001;96:2905-14. doi:10.1111/j.1572$0241.2001 .04680 . x$

6 Halder SLS, Locke GR3rd, Schleck CD, Zinsmeister AR, Melton LI3rd, Talley NJ. Natural history of functional gastrointestinal disorders: a 12-year longitudinal population-based study. Gastroenterology 2007;133:799-807. doi:10.1053/j. gastro.2007.06.010

7 Ford AC, Forman D, Bailey AG, Axon AT, Moayyedi P. Fluctuation of gastrointestinal symptoms in the community: a 10-year longitudinal follow-up study. Aliment Pharmacol Ther 2008;28:1013-20. doi:10.1111/j.1365-2036.2008.03813x

8 Enck P, Dubois D, Marquis P. Quality of life in patients with upper gastrointestinal symptoms: results from the Domestic/ International Gastroenterology Surveillance Study (DIGEST). Scand / Gastroenterol Suppl 1999;231(suppl 231):48-54. doi:10.1080/003655299750025264

9 Camilleri M, Dubois D, Coulie B, et al. Prevalence and socioeconomic impact of upper gastrointestinal disorders in the United States: results of the US Upper Gastrointestinal Study. Clin Gastroenterol Hepatol 2005;3:543-52. doi:10.1016/S1542-3565(05)00153-9

10 Brook RA, Kleinman NL, Choung RS, Melkonian AK, Smeeding JE, Talley NJ. Functional dyspepsia impacts absenteeism and direct and indirect costs. Clin Gastroenterol Hepatol 2010;8:498-503. doi:10.1016/j.cgh.2010.03.003

11 Lacy BE, Weiser KT, Kennedy AT, Crowell MD, Talley NJ. Functional dyspepsia: the economic impact to patients. Aliment Pharmacol Ther 2013;38:170-7. doi:10.1111/apt.12355

12 Ford AC, Forman D, Bailey AG, Cook MB, Axon AT, Moayyedi P. Who consults with dyspepsia? Results from a longitudinal 10-yr follow-up study. Am J Gastroenterol 2007;102:957-65. doi:10.1111/j.15720241.2007.01080.x

13 Bytzer P, Hansen JM, Schaffalitzky de Muckadell OB. Empirical H2blocker therapy or prompt endoscopy in management of dyspepsia. Lancet 1994;343:811-6. doi:10.1016/S0140-6736(94)92023-0

14 Delaney BC, Qume M, Moayyedi P, et al. Helicobacter pylori test and treat versus proton pump inhibitor in initial management of dyspepsia in primary care: multicentre randomised controlled trial (MRC-CUBE trial). BM/ 2008;336:651-4. doi:10.1136/ bmj.39479.640486.AE

15 Delaney BC, Wilson S, Roalfe A, et al. Cost effectiveness of initial endoscopy for dyspepsia in patients over age 50 years: a randomised controlled trial in primary care. Lancet 2000;356:19659. doi:10.1016/S0140-6736(00)03308-0

16 Delaney BC, Wilson S, Roalfe A, et al. Randomised controlled trial of Helicobacter pylori testing and endoscopy for dyspepsia in primary care. BMJ 2001;322:898-901. doi:10.1136/bmj.322.7291.898

17 McColl KEL, Murray LS, Gillen D, et al. Randomised trial of endoscopy with testing for Helicobacter pylori compared with noninvasive $\mathrm{H}$ pylori testing alone in the management of dyspepsia. BMJ 2002;324:999-1002. doi:10.1136/bmj.324.7344.999

18 Duggan AE, Elliott CA, Miller P, Hawkey CJ, Logan RF. Clinical trial: a randomized trial of early endoscopy, Helicobacter pylori testing and empirical therapy for the management of dyspepsia in primary care. Aliment Pharmacol Ther 2009;29:55-68. doi:10.1111/j.13652036.2008.03852.x

19 Ford AC, Qume M, Moayyedi P, et al. Helicobacter pylori "test and treat" or endoscopy for managing dyspepsia: an individual patient data meta-analysis. Gastroenterology 2005;128:1838-44. doi:10.1053/i.gastro.2005.03.004

20 Moayyedi P, Lacy BE, Andrews CN, Enns RA, Howden CW, Vakil N. ACG and CAG clinical guideline: management of dyspepsia. Am J Gastroenterol 2017;112:988-1013. doi:10.1038/ajg.2017.154 
21 Dyspepsia and gastro-oesophageal reflux disease: Investigation and management of dyspepsia, symptoms suggestive of gastrooesophageal reflux disease, or both. https://www.nice.org.uk/ guidance/cg184 2014

22 Ford AC, Moayyedi P, Jarbol DE, Logan RF, Delaney BC. Metaanalysis: Helicobacter pylori 'test and treat' compared with empirical acid suppression for managing dyspepsia. Aliment Pharmacol Ther 2008;28:534-44. doi:10.1111/j.1365-2036.2008.03784.x

23 Talley NJ, Lam SK, Goh KL, Fock KM. Management guidelines for uninvestigated and functional dyspepsia in the AsiaPacific region: First Asian Pacific Working Party on Functional Dyspepsia. J Gastroenterol Hepatol 1998;13:335-53. doi:10.1111/j.1440-1746.1998.tb00644.x

24 Boutron I, Page MJ, Higgins JPT, et al. Chapter 7: Considering bias and conflicts of interest among the included studies. In: Higgins JPT, Thomas J, Chandler J, et al. (eds), Cochrane Handbook for Systematic Reviews of Interventions version 6.0 (updated July 2019). Cochrane, 2019. http://www.training.cochrane.org/handbook

25 Rücker G, Schwarzer G. Reduce dimension or reduce weights? Comparing two approaches to multi-arm studies in network metaanalysis. Stat Med 2014;33:4353-69. doi:10.1002/sim.6236

26 Hutton B, Salanti G, Caldwell DM, et al. The PRISMA extension statement for reporting of systematic reviews incorporating network meta-analyses of health care interventions: checklist and explanations. Ann Intern Med 2015;162:777-84. doi:10.7326/ M14-2385

27 Salanti G, Higgins JP, Ades AE, loannidis JP. Evaluation of networks of randomized trials. Stat Methods Med Res 2008;17:279-301. doi:10.1177/0962280207080643

28 Salanti G. Indirect and mixed-treatment comparison, network, or multiple-treatments meta-analysis: many names, many benefits, many concerns for the next generation evidence synthesis tool. Res Synth Methods 2012:3:80-97. doi:10.1002/jrsm.1037

29 Salanti G, Ades AE, loannidis JP. Graphical methods and numerical summaries for presenting results from multiple-treatment metaanalysis: an overview and tutorial. / Clin Epidemiol 2011;64:163-71. doi:10.1016/j.jclinepi.2010.03.016

30 Chaimani A, Higgins JP, Mavridis D, Spyridonos P, Salanti G. Graphical tools for network meta-analysis in STATA. PLoS One 2013;8:e76654. doi:10.1371/journal.pone.0076654

31 Higgins JP, Jackson D, Barrett JK, Lu G, Ades AE, White IR. Consistency and inconsistency in network meta-analysis: concepts and models for multi-arm studies. Res Synth Methods 2012;3:98-110. doi:10.1002/jrsm.1044

32 Higgins JPT, Thompson SG, Deeks JJ, Altman DG. Measuring inconsistency in meta-analyses. BMJ 2003;327:557-60. doi:10.1136/bmj.327.7414.557

33 Rücker G, Schwarzer G, Carpenter JR, Schumacher M. Undue reliance on I(2) in assessing heterogeneity may mislead. BMC Med Res Methodol 2008;8:79. doi:10.1186/1471-2288-8-79

34 da Costa BR, Juni P. Systematic reviews and meta-analyses of randomized trials: principles and pitfalls. Eur Heart J 2014;35:3336 45. doi:10.1093/eurhearti/ehu424

35 Krahn U, Binder H, König J. A graphical tool for locating inconsistency in network meta-analyses. BMC Med Res Methodol 2013;13:35. doi:10.1186/1471-2288-13-35

36 Rücker G. Network meta-analysis, electrical networks and graph theory. Res Synth Methods 2012;3:312-24. doi:10.1002/ jrsm.1058

37 Rücker G, Schwarzer G. Ranking treatments in frequentist network meta-analysis works without resampling methods. BMC Med Res Methodol 2015;15:58. doi:10.1186/s12874-015-0060-8

38 Morton SC, Murad MH, O'Connor E, et al. AHRQ methods for effective health care. Quantitative synthesis-an update. Methods Guide for Effectiveness and Comparative Effectiveness Reviews. Rockville (MD). Agency for Healthcare Research and Quality, 2018.

39 Brown S, Hutton B, Clifford T, et al. A Microsoft-Excel-based tool for running and critically appraising network meta-analyses--an overview and application of NetMetaXL. Syst Rev 2014;3:110. doi:10.1186/2046-4053-3-110

40 Black CJ, Burr NE, Camilleri M, et al. Efficacy of pharmacological therapies in patients with IBS with diarrhoea or mixed stool pattern: systematic review and network meta-analysis. Gut 2019; gutjnl-2018-318160. doi:10.1136/gutjnl-2018-318160

41 Black CJ, Burr NE, Quigley EMM, Moayyedi P, Houghton LA, Ford AC. Efficacy of secretagogues in patients with irritable bowel syndrome with constipation: Systematic review and network metaanalysis. Gastroenterology 2018;155:1753-63. doi:10.1053/j. gastro.2018.08.021

42 Luthra P, Burr NE, Brenner DM, Ford AC. Efficacy of pharmacological therapies for the treatment of opioid-induced constipation: systematic review and network meta-analysis. Gut 2018;68:434-44. doi:10.1136/gutinl-2018-316001

43 Luthra P, Camilleri M, Burr NE, Quigley EMM, Black CJ, Ford AC. Efficacy of drugs in chronic idiopathic constipation: a systematic review and network meta-analysis. Lancet Gastroenterol Hepatol 2019;4:831-44. doi:10.1016/S2468-1253(19)30246-8

44 Black C), Burr NE, Ford AC. Relative efficacy of tegaserod in a systematic review and network meta-analysis of licensed therapies for irritable bowel syndrome with constipation. Clin Gastroenterol Hepatol 2019:S1542-3565(19)30740-2. doi:10.1016/j. cgh.2019.07.007

45 Jarbol DE, Kragstrup J, Stovring H, Havelund T, Schaffalitzky de Muckadell OB. Proton pump inhibitor or testing for Helicobacter pylori as the first step for patients presenting with dyspepsia? A cluster-randomized trial. Am J Gastroenterol 2006;101:1200-8. doi:10.1038/ajg2006227

46 Rao JNK, Scott AJ. A simple method for the analysis of clustered binary data. Biometrics 1992;48:577-85. doi:10.2307/2532311

47 Whiting-O'Keefe QE, Henke C, Simborg DW. Choosing the correct unit of analysis in Medical Care experiments. Med Care 1984;22:110114. doi:10.1097/00005650-198412000-00005

48 Heaney A, Collins JSA, Watson RGP, McFarland RJ, Bamford KB, Tham TC. A prospective randomised trial of a "test and treat" policy versus endoscopy based management in young Helicobacter pylori positive patients with ulcer-like dyspepsia, referred to a hospital clinic. Gut 1999;45:186-90. doi:10.1136/gut.45.2.186

49 Lassen AT, Pedersen FM, Bytzer P, Schaffalitzky de Muckadell OB. Helicobacter pylori test-and-eradicate versus prompt endoscopy for management of dyspeptic patients: a randomised trial. Lancet 2000:356:455-60 doi:10.1016/S0140-6736(00)02553-8

50 Arents NLA, Thijs JC, van Zwet AA, et al. Approach to treatment of dyspepsia in primary care: a randomized trial comparing "test-andtreat" with prompt endoscopy. Arch Intern Med 2003;163:1606-12 doi:10.1001/archinte.163.13.1606

51 Mahadeva S, Chia YC, Vinothini A, Mohazmi M, Goh KL. Costeffectiveness of and satisfaction with a Helicobacter pylori "test and treat" strategy compared with prompt endoscopy in young Asians with dyspepsia. Gut 2008;57:1214-20. doi:10.1136/ gut.2007.147728

52 Manes G, Menchise A, de Nucci C, Balzano A. Empirical prescribing for dyspepsia: randomised controlled trial of test and treat versus omeprazole treatment. BMJ 2003;326:1118. doi:10.1136/ bmj.326.7399.1118

53 Kjeldsen HC, Bech M, Christensen B. Cost-effectiveness analysis of two management strategies for dyspepsia. Int J Technol Assess Health Care 2007;23:376-84. doi:10.1017/S0266462307070420

54 Lewin van den Broek NT, Numans ME, Buskens E, Verheij TJ, de Wit $\mathrm{NJ}$, Smout AJ. A randomised controlled trial of four management strategies for dyspepsia: relationships between symptom subgroups and strategy outcome. Br J Gen Pract 2001;51:619-24.

55 Delaney BC, Ford AC, Forman D, et al. Initial management strategies for dyspepsia. Cochrane Library, Issue 2. John Wiley \& Sons, 2005.

56 Ford AC, Marwaha A, Lim A, Moayyedi P. What is the prevalence of clinically significant endoscopic findings in subjects with dyspepsia? Systematic review and meta-analysis. Clin Gastroenterol Hepatol 2010;8:830-7, 837.e1-2. doi:10.1016/j.cgh.2010.05.031

57 Vakil N, Talley N, van Zanten SV, et al, STARS I Study Group. Cost of detecting malignant lesions by endoscopy in 2741 primary care dyspeptic patients without alarm symptoms. Clin Gastroenterol Hepatol 2009;7:756-61. doi:10.1016/i.cgh.2009.03.031

58 Lucock MP, Morley S, White C, Peake MD. Responses of consecutive patients to reassurance after gastroscopy: results of self administered questionnaire survey. BMJ 1997;315:572-5. doi:10.1136/ bmj.315.7108.572

59 Yang YX, Brill J, Krishnan P, Leontiadis G, American Gastroenterological Association Clinical Practice Guidelines Committee. American Gastroenterological Association Institute guideline on the role of upper gastrointestinal biopsy to evaluate dyspepsia in the adult patient in the absence of visible mucosal lesions. Gastroenterology 2015;149:1082-7. doi:10.1053/j. gastro.2015.07.039

60 Moayyedi P, Soo S, Deeks J, et al, Dyspepsia Review Group. Systematic review and economic evaluation of Helicobacter pylori eradication treatment for non-ulcer dyspepsia. BMJ 2000;321:65964. doi:10.1136/bmj.321.7262.659

61 Sugano K, Tack J, Kuipers EJ, et al, faculty members of Kyoto Global Consensus Conference. Kyoto global consensus report on Helicobacter pylori gastritis. Gut 2015;64:1353-67. doi:10.1136/ gutjnl-2015-309252

62 Ford AC, Forman D, Bailey AG, Axon AT, Moayyedi P. A community screening program for Helicobacter pylori saves money: 10-year follow-up of a randomized controlled trial. Gastroenterology 2005;129:1910-7. doi:10.1053/j. gastro.2005.09.016

63 Ford AC, Forman D, Hunt RH, Yuan Y, Moayyedi P. Helicobacter pylori eradication therapy to prevent gastric cancer in healthy asymptomatic infected individuals: systematic review and metaanalysis of randomised controlled trials. BMJ 2014;348:93174. doi:10.1136/bmj.g3174 
64 Barton PM, Moayyedi P, Talley NJ, Vakil NB, Delaney BC. A secondorder simulation model of the cost-effectiveness of managing dyspepsia in the United States. Med Decis Making 2008;28:44-55. doi:10.1177/0272989X07309644

65 Moayyedi P, Delaney BC, Vakil N, Forman D, Talley NJ. The efficacy of proton pump inhibitors in nonulcer dyspepsia: a systematic review and economic analysis. Gastroenterology 2004;127:1329-37. doi:10.1053/j.gastro.2004.08.026

66 Vaezi MF, Yang YX, Howden CW. Complications of proton pump inhibitor therapy. Gastroenterology 2017;153:35-48. doi:10.1053/j. gastro.2017.04.047

67 Pittayanon R, Yuan Y, Bollegala NP, et al. Prokinetics for functional dyspepsia: a systematic review and meta-analysis of randomized control trials. Am J Gastroenterol 2019;114:233-43. doi:10.1038/ s41395-018-0258-6

68 Ford AC, Luthra P, Tack J, Boeckxstaens GE, Moayyedi P, Talley NJ. Efficacy of psychotropic drugs in functional dyspepsia: systematic review and meta-analysis. Gut 2017;66:411-20. doi:10.1136/ gutjnl-2015-310721

69 Ford AC, Lacy BE, Harris LA, Quigley EMM, Moayyedi P. Effect of antidepressants and psychological therapies in irritable bowel syndrome: an updated systematic review and meta-analysis. Am Gastroenterol 2019:114:21-39 doi:10.1038/s41395-0180222-5

70 Drossman DA, Tack J, Ford AC, Szigethy E, Törnblom H, Van Oudenhove L. Neuromodulators for functional gastrointestinal disorders (disorders of gut-brain interaction): a Rome Foundation working team report. Gastroenterology 2018;154:1140-1171.e1. doi:10.1053/j.gastro.2017.11.279

Web appendix: Supplementary material 